\title{
A New Optimization Algorithm for Checking and Sorting Project Schedules
}

\author{
Huilin Yuan ${ }^{1,3}$, Wei Liu ${ }^{2, *}$, Jinbo Chao ${ }^{4}$ and Leizhen Wang ${ }^{3}$ \\ ${ }^{I}$ Beijing University of Aeronautics and Astronautics Mechanical Engineering Post-doctoral Mobile Station, Beijing \\ 100083, China \\ ${ }^{2}$ Qinhuangdao Haisan Construction and Project-developing Co. Ltd., Qinhuangdao 066000, China \\ ${ }^{3}$ Northeastern University at Qinhuangdao, Qinhuangdao 066004, China \\ ${ }^{4}$ Yanshan University, Qinhuangdao 066004, China
}

\begin{abstract}
The overall project schedule is the basement of construction project. Any problem in it will cause huge economic loses, and it must be checked before being implemented. This paper introduces real value into DSM (design structure matrix), proposes a new checking and sorting method, and designs detailed processes and rules. Additionally the effectiveness of the method is proved through applying it to an example.
\end{abstract}

Keywords: Project Schedule, Sorting, DSM, Topology.

\section{INTRODUCTION}

Building projects can be complex. They demand accurate project scheduling and task management to ensure they go to plan. Before the start of the project, the General Contracting Unit should prepare its overall project schedule which is implemented after it is approved by the supervision, the project company, and then the project management division, vice-president. The overall progress of the program should define measure, requirements and station time of each subunit, and provide a time reference. The General Contracting Unit must be liable for breach, if construction period delay is caused by the inaccurate overall schedule. So the overall schedule must be checked before being implemented.

First, the project Gantt chart, as shown in Fig. (1), should be developed in the project schedule progress. The basic requirement of the project: a project must begin after its preproject having been completed. This means that the progress must be sorted and checked according to the requirement.

The project Gantt chart must be checked first because of plenty of projects and long duration. Detection method commonly used is to convert it into a AOE network, then the AOE is topologically sorted. [1,2] Traditional topological sorting method first inputs AOE network, then finds a vertex which hasn't a direct precursor, outputs and deletes it, the process is repeat $\mathrm{N}$ (the number of vertices) times; if the process stops before $\mathrm{N}$ times, that means the project schedule is wrong. There are 26 points in a simplified AOE as showed in Fig. (2), if it is right, the sorting repeat 26 times, otherwise, the schedule must be done again from beginning.

\section{DSM SORTING METHOD}

\subsection{DSM}

There has already been an excellent review by Browning in general areas of DSM application. They categorized DSM models into four types according to their characteristics and applications:

1) Component-Based DSM: which documents interactions among product components, can be used to facilitate appropriate modularization of a complex system;

2) Team-Based DSM, useful for depicting the interactions among design teams;

3) Activity-Based DSM, effective in modelling the information dependencies among design activities;

4) Parameter-Based DSM, for documenting physical design parameter relationships. Please read through the following sections for more information on preparing your paper. However, if you use the template you do not have to worry about setting margins, page size, and column size etc. as the template already has the correct dimensions.

Iteration, the repetition of design tasks, is a fundamental characteristic of design process. Iteration occurred in product development for two main reasons. First, tasks may need to be reworked when review or testing activities detect some faults in the original design. Second, when modified information is passed along from upstream, some of the downstream work may be obsolete and need be reworked. 


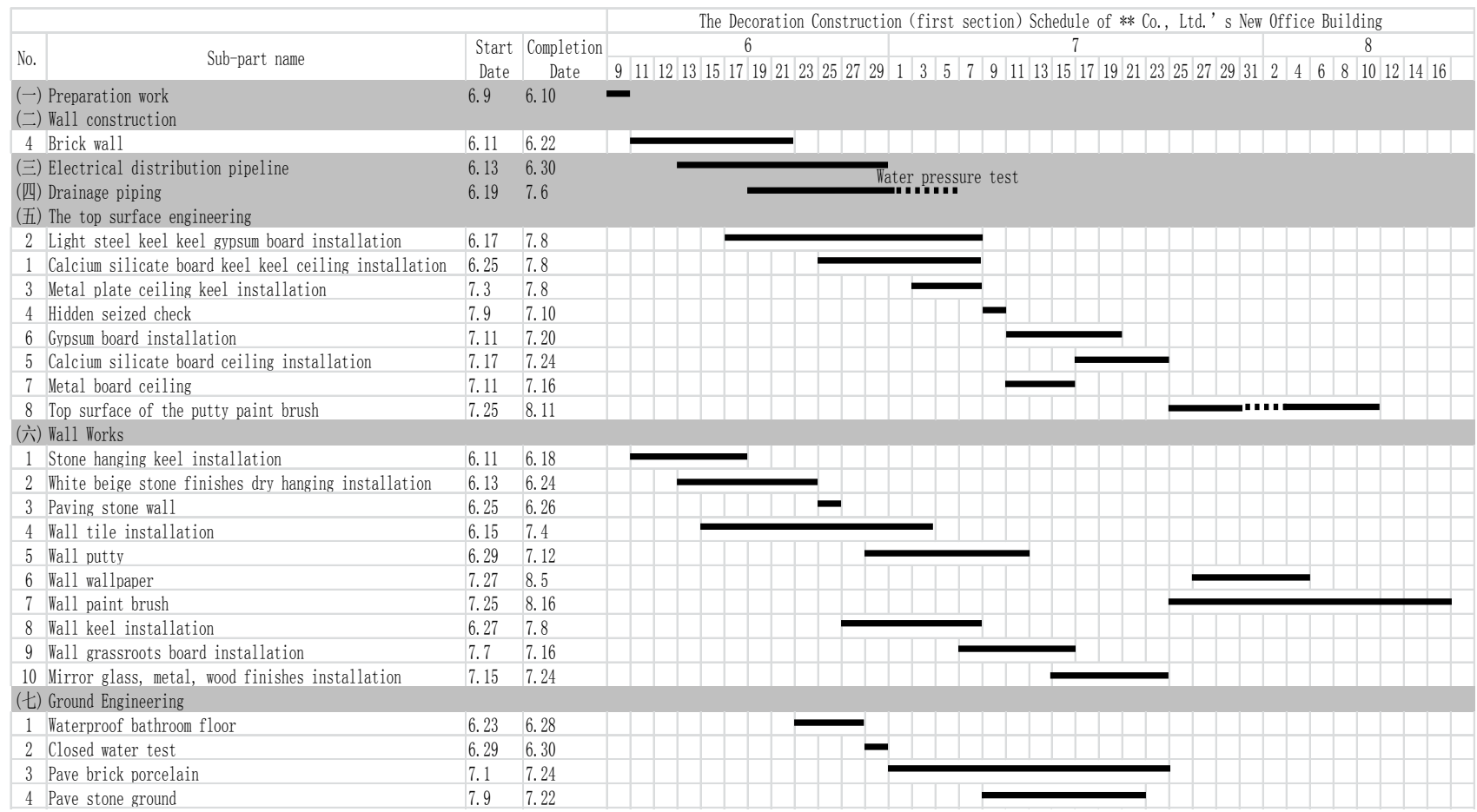

Fig. (1). The gantt chart of a project.

The iterative nature of product development can be addressed by using DSM. As shown in Fig. (2), the basic DSM is a binary matrix representation of a project with elements denoting individual design tasks and off diagonal marks representing the information dependencies among these tasks. Along each row, the off diagonal marks indicate all of the tasks whose output information is required to perform the task corresponding to that row. Reading down each column reveals that which other tasks receive its output. When activities are executed in the order listed from top to bottom, sub diagonal marks represent an input from upstream activities/stages to downstream activities/stages. Super diagonal marks denote a feedback from downstream activities to upstream activities. As such, the DSM approach provides a concise way in describing and investigating information transfer and iteration. follow:

The principal concepts of DSM can be summarized as

1) DPs of a system are intuitively elicited, often based on experience.

2) Dependencies between the DPs are represented in matrix form Fig. (3).

3) An ' $X$ ' in the matrix indicates a dependency between two DPs - the row-DP depends on the column-DP.

4) DP2 is concluded to be dependent on DP1, when DP1 is an input to DP2 - modifying DP1 affects DP2

5) Modular design (modularity) is achieved by clustering inter-dependent DPs, and by information hiding, to form modules.
6) Modules are units in a larger system that are structurally independent of one another, but work together $[5,6]$.

\subsection{DSM Sorting Method}

With development of research on Design Structure Matrix (DSM), DSM is widely used in construction, semiconductor, automation, photography, aviation, communications, small-scale manufacturing, assembly plant, e-business, project planning and control, product development, workflow, software development and other fields. Disadvantage of DSM is that the matrix elements are some vague values: Most use Boolean constant, the symbol "X", "•" and other information to indicate the interaction between activities. Later the matrix elements are modified by numbers, which only show the degree of dependence between activities, so that the application of DSM modelling and optimization is still qualitative, and unable to meet the Quantitative characteristics of the project processes [3-7].

This paper presents a method based on improved DSM: first it will reduce the complication of the network, and then improve efficiency of the algorithm, while also record the specific project which does not meet the requirement, targeted the wrong parts in the schedule.

The elements of DSM are modified by real value, and the process of the DSM sorting method is designed as follows:

Step 1. Input AOE and establish DSM matrix A according to equation (1). 


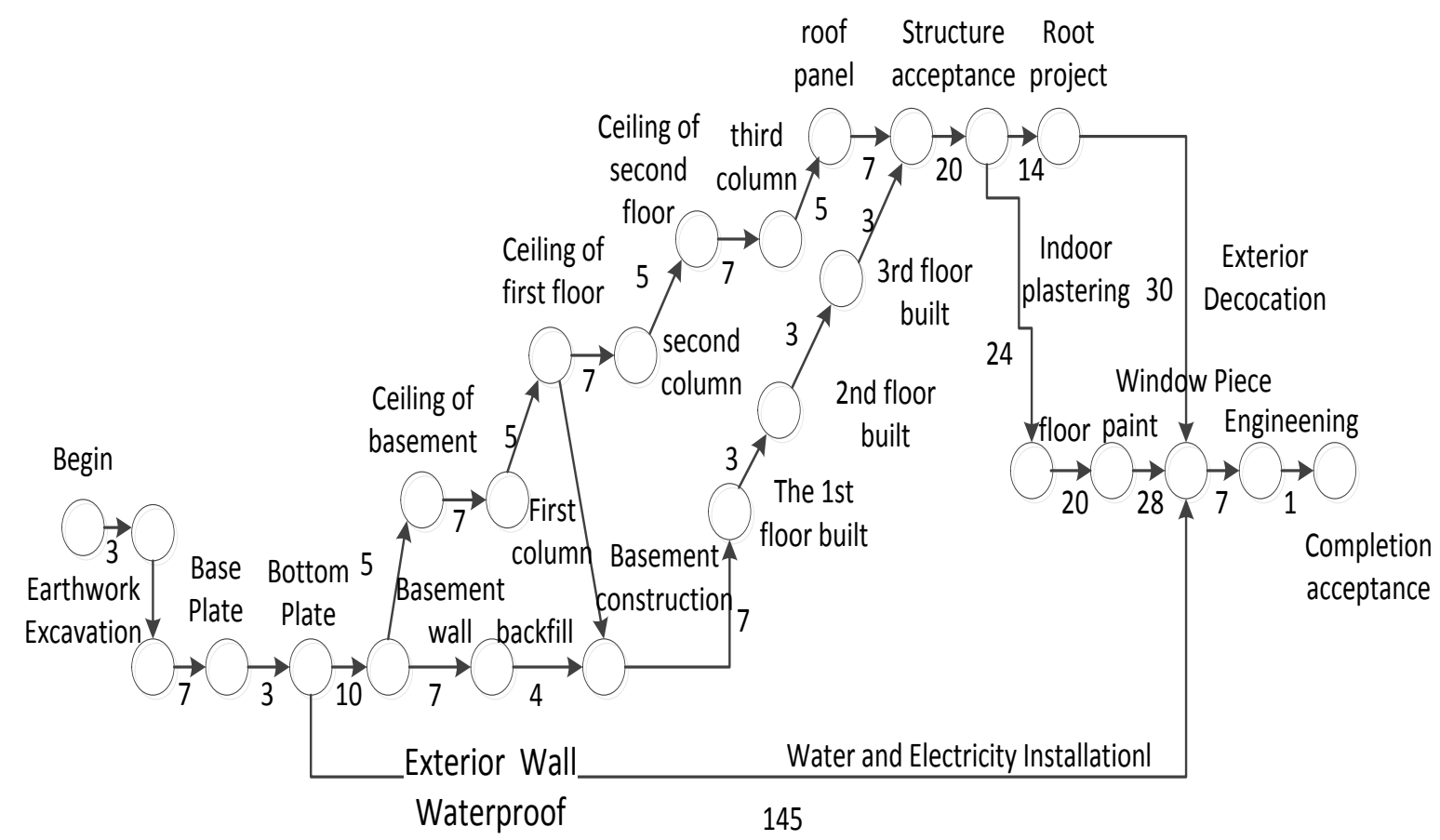

Fig. (2). AOE simplified from a gantt chart.

\begin{tabular}{|l|l|l|l|l|l|l|l|l|}
\hline Activities & & 1 & 2 & 3 & 4 & 5 & 6 & 7 \\
\hline Architecture Layout & 1 & & & & & & & \\
\hline Incustrious Design & 2 & $x$ & & $x$ & & & & \\
\hline Mechanical Design & 3 & $x$ & $x$ & & $x$ & & & \\
\hline PCB layout & 4 & $x$ & & $x$ & & & & \\
\hline Software Design & 5 & $x$ & & & & & & \\
\hline Prototyping & 6 & & $x$ & $x$ & $x$ & $x$ & & \\
\hline Testing & 7 & & & & & & $x$ & \\
\hline
\end{tabular}

Fig. (3). Example of design structure matrix.

$A=\left[a_{i j}\right]_{n \times n}, a_{i j}= \begin{cases}W(i, j), & \text { if } i \neq j \text { and } i \text { is adjacent to } \mathrm{j} \\ 0, & \text { else. }\end{cases}$

Step 2. Cluster or combine activities. If one point have only one pre-activity and one post-activity, they can be merged as one activity, the value of it is pre-activity's plus post-activity's $\left(a_{i j}=a_{i j}+a_{j k}\right)$. This step is always done with Step 3 together.

Step 3. Adjust the order of activities. In A, nonzero element in the row display the flow of information required to carry out the activity, and in the column indicates that the output flow of the activity. If all the elements of a row on A are zero, the activity responding to this row should be executed as early as possible, because it is the source point of the whole activity process and does not need any information of other activities. We adjust it on the first row and column on A, and mark the activities (which need information flow of this point) as candidate sources.

If all the elements of a column are zero, the activity responding to this column should be executed behind other activities, because it is the terminal point and provides no information to the others. We put it on the last column and row on A and mark the activities (which flow information in this point) as candidate meeting point.

Step 4. In a similar way, we can adjust other activities on $\mathrm{A}$ in turn. 
Step 5. Let the number of activities is n. If the activity does not exist with the ring, then the process goes through from step 3 to 5 for $(n+1) / 2$ times, all sorts of activities will be sorted in sequence. Otherwise, when there are rings, the algorithm goes to step 6 .

Step 6. Identify rings according to equation (2).

$$
Q_{p}=A+A^{\mathrm{T}}, \quad 0+a_{i j}=0
$$

The values in the same ring are same. For example, the figure below shows DSMA of a AOE. And the $Q_{p}$ is gained. From the matrix the activity ' 3 ', ' 4 ' and ' 5 ' are in the same ring. So the problem of the schedule may occur in it, further check is focused on its platform.

$$
A=\left(\begin{array}{ccccccc}
0 & 1 & 3.2 & 6.7 & 8.7 & 8.7 & 11.2 \\
0 & 0 & 2.2 & 5.7 & 7.7 & 7.7 & 10.2 \\
0 & 0 & 0 & 3.5 & 5.5 & 5.5 & 8 \\
0 & 0 & 5 & 0 & 2 & 2 & 4.5 \\
0 & 0 & 3 & 6.5 & 0 & 8.5 & 11 \\
0 & 0 & 0 & 0 & 0 & 0 & 2.5 \\
0 & 0 & 0 & 0 & 0 & 0 & 0
\end{array}\right)
$$

$$
Q_{p}=\left(\begin{array}{ccccccc}
0 & 0 & 0 & 0 & 0 & 0 & 0 \\
0 & 0 & 0 & 0 & 0 & 0 & 0 \\
0 & 0 & 0 & 8.5 & 8.5 & 0 & 0 \\
0 & 0 & 8.5 & 0 & 8.5 & 0 & 0 \\
0 & 0 & 8.5 & 8.5 & 0 & 0 & 0 \\
0 & 0 & 0 & 0 & 0 & 0 & 0 \\
0 & 0 & 0 & 0 & 0 & 0 & 0
\end{array}\right)
$$

\section{CHECKING ON A PROJECT SCHEDULE}

First DSM A of the AOE showed in Fig. (2) is Gained as follows according Equation (1).

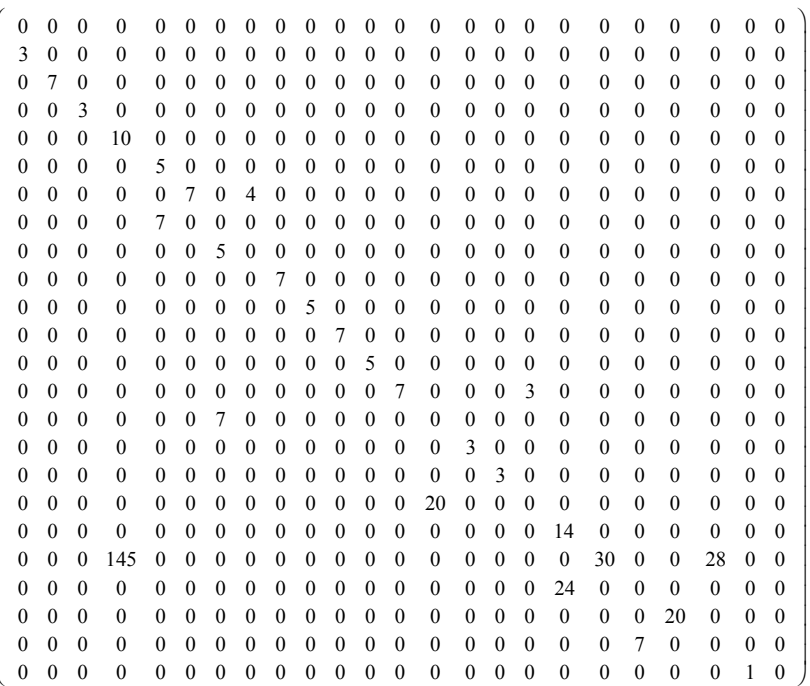

Then cluster the matrix according Step 2: 'earthwork', 'excavation', 'base plate' and 'bottom plate' are combined into one activity, valuing ' 13 ', and the matrix become as follows:

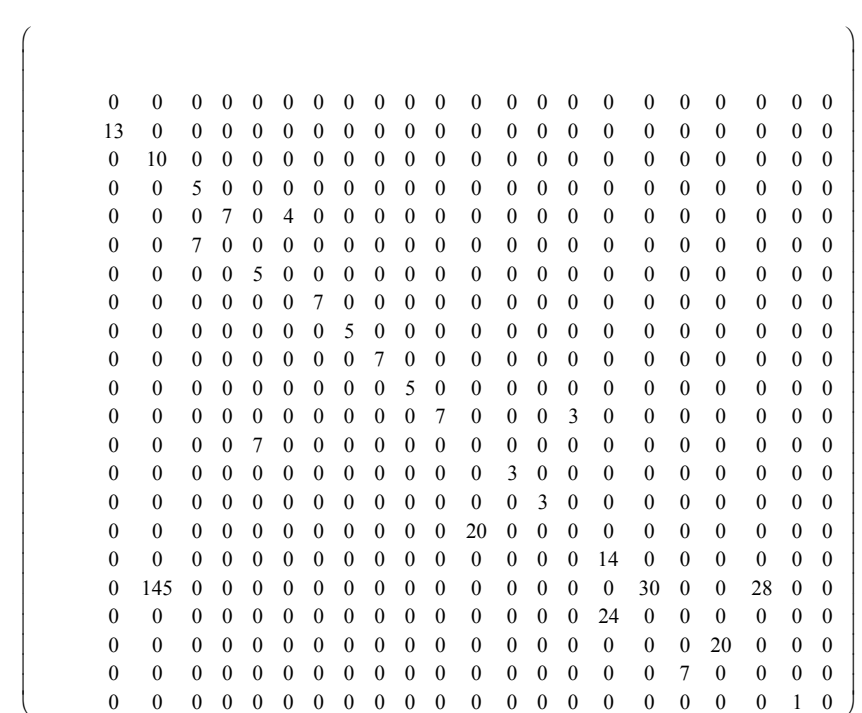

'Basement', 'ceiling of basement' and 'first column' are combined into one activity, valuing $17 ; \ldots$; 'engineering' and 'completion acceptance' are combined into one activity, valuing 8; at last the number of the activities is 11 , and the matrix below shows results.

$\left(\begin{array}{ccccccccccc}0 & 0 & 0 & 0 & 0 & 0 & 0 & 0 & 0 & 0 & 0 \\ 13 & 0 & 0 & 0 & 0 & 0 & 0 & 0 & 0 & 0 & 0 \\ 0 & 10 & 0 & 0 & 0 & 0 & 0 & 0 & 0 & 0 & 0 \\ 0 & 0 & 17 & 0 & 4 & 0 & 0 & 0 & 0 & 0 & 0 \\ 0 & 0 & 7 & 0 & 0 & 0 & 0 & 0 & 0 & 0 & 0 \\ 0 & 0 & 0 & 31 & 0 & 3 & 0 & 0 & 0 & 0 & 0 \\ 0 & 0 & 0 & 13 & 0 & 0 & 0 & 0 & 0 & 0 & 0 \\ 0 & 0 & 0 & 0 & 0 & 20 & 0 & 0 & 0 & 0 & 0 \\ 0 & 145 & 0 & 0 & 0 & 0 & 0 & 44 & 0 & 28 & 0 \\ 0 & 0 & 0 & 0 & 0 & 0 & 0 & 44 & 0 & 0 & 0 \\ 0 & 0 & 0 & 0 & 0 & 0 & 0 & 0 & 8 & 0 & 0\end{array}\right)$

And then the matrix is sorted 6 times according to Step 3, the matrix above shows the results. The matrix shows: there is no ring in the schedule; sequences of the project can be gained. Based on it, the further work (such as calculating critical path, optimization, and so on) can be done.

$\left(\begin{array}{ccccccccccc}0 & 0 & 0 & 0 & 0 & 0 & 0 & 0 & 0 & 0 & 0 \\ 13 & 0 & 0 & 0 & 0 & 0 & 0 & 0 & 0 & 0 & 0 \\ 0 & 10 & 0 & 0 & 0 & 0 & 0 & 0 & 0 & 0 & 0 \\ 0 & 0 & 7 & 0 & 0 & 0 & 0 & 0 & 0 & 0 & 0 \\ 0 & 0 & 12 & 4 & 0 & 0 & 0 & 0 & 0 & 0 & 0 \\ 0 & 0 & 0 & 0 & 13 & 0 & 0 & 0 & 0 & 0 & 0 \\ 0 & 0 & 0 & 0 & 31 & 3 & 0 & 0 & 0 & 0 & 0 \\ 0 & 0 & 0 & 0 & 0 & & 20 & 0 & 0 & 0 & 0 \\ 0 & 0 & 0 & 0 & 0 & 0 & 0 & 44 & 0 & 0 & 0 \\ 0 & 145 & 0 & 0 & 0 & 0 & 0 & 44 & 28 & 0 & 0 \\ 0 & 0 & 0 & 0 & 0 & 0 & 0 & 0 & 0 & 8 & 0\end{array}\right)$




\section{CONCLUSION}

The overall project schedule is the basement of a construction project, but it goes wrong sometimes because of large number of projects in it. So the schedule must be checked before being implemented. In this paper, real values were introduced into DSM, and a new topological method was proposed. At last, the example showed that the method could reduce the number of activities and shorten the time, so it is more effective compared to the traditional method.

\section{CONFLICT OF INTEREST}

The authors confirm that this article content has no conflict of interest.

\section{ACKNOWLEDGEMENTS}

This work is sponsored by the National Natural Science Fund \#60821063 and Science and Technology Plan Project of Hebei Province \#13214716.
The authors are grateful to the valuable and constructive comments from the editor and anonymous referees.

\section{REFERENCES}

[1] Baidu Encyclopedia, Information on http://baike.baidu.com/link?url=dMqWIKxoYn9KohPJyPERxG1tWwm5ivuVR5gGOwF9 k G3fRnG4OY-SDQp0g_rfaUhgRUi-8MrycAE7VytiLmCsq

[2] R. Yin, Data Structure, Tsinghua university press, Beijing, 2012.

[3] D.V. Steward, "The design structure system: a method for managing the design of complex systems" IEEE Transactions on Engineering Management, vol. 78, no. 3, pp. 71-74, 1981.

[4] H. Yuan, and D. Wang, "The New Approach of Marking Activityloops Based on the String Reachable Matrix" In: International Conference on Communications and Mobile Computing (CMC 2009) Kunming, vol. 3,pp. 569-572, 2009.

[5] A. Avritzer, D. Paulish, and Y. Cai, "Coordination Implications of Software Architecture in a Global Software Development Project" In: $7^{\text {th }}$ Working IEEE/IFIP Conference on Software Architecture, 2008.

[6] L. Zhang, L. Zhang, Z. Wang, and S. Jia, "A method for the shortest distance routing in a chart based on testing a spatial relation of a route segment and an obstacle area" In: 2010 2nd International Conference on Advanced Computer Control (ICACC 2010), pp. 142-147.

[7] Wikipedia, Information on http://en.wikipedia.org/_wiki/Design_struc-ture_matrix

(C) Yuan et al.; Licensee Bentham Open.

This is an open access article licensed under the terms of the Creative Commons Attribution Non-Commercial License (http://creativecommons.org/licenses/by-nc/3.0/) which permits unrestricted, non-commercial use, distribution and reproduction in any medium, provided the work is properly cited. 